\title{
Use of Shuttle Heritage Hardware in Space Launch System (SLS) Application - Structural Assessment
}

James N. Booker Pravin Aggarwal 
- We appreciate the word done by a team of engineers and technicians at MSFC and Orbital ATK in developing and executing the test and analysis to help establish the flight rationale for the shuttle heritage hardware for use on SLS. This paper takes advantage of reports published to document the test and analysis for developing the flight rationale and was not possible otherwise. However, these reference are not cited herein due to potential conflict with International traffic in Arms Regulations (ITAR) 


\section{Introduction}

- NASA is aggressively moving forward with development of the next generation human spaceflight system to meet the Nation's human space exploration goals as expressed in the 2011 NASA Strategic Plan

- Strategic Goal 1 - Extend and sustain human activities across the solar system

- Strategic Goal 1.3 - Develop integrated architecture capabilities for safe crewed and cargo missions beyond low Earth orbit

- To meet this goal with limited resources and with an expedited schedule, Affordability Safety, \& sustainability are the key tenants

- Use of existing hardware in inventory from previous programs offers increased cost savings - i.e., AFFORDABILITY

The Space Launch System (SLS) is a heavy-lift launch vehicle currently being designed to meet these goals

- SLS Block 1 architecture is the configuration for the first flight: EM-1

- Block 1 includes Heritage: Solid Rocket Boosters and RS-25 Engines, New: Core Stage, Integrated Spacecraft and Payload Element (ISPE), Launch Vehicle Stage Adapter (LVSA), Separation System, MPCV Stage Adapter (MSA) Cryogenic Propulsion Stage

- Heritage Boosters, left over from the Shuttle Program, will be used to provide the major ascent thrust to the Vehicle

- Qualification of heritage hardware to all structural and functional requirements of the SLS program provided significant challenges ensuring SAFETY 


\section{SIS SLS}

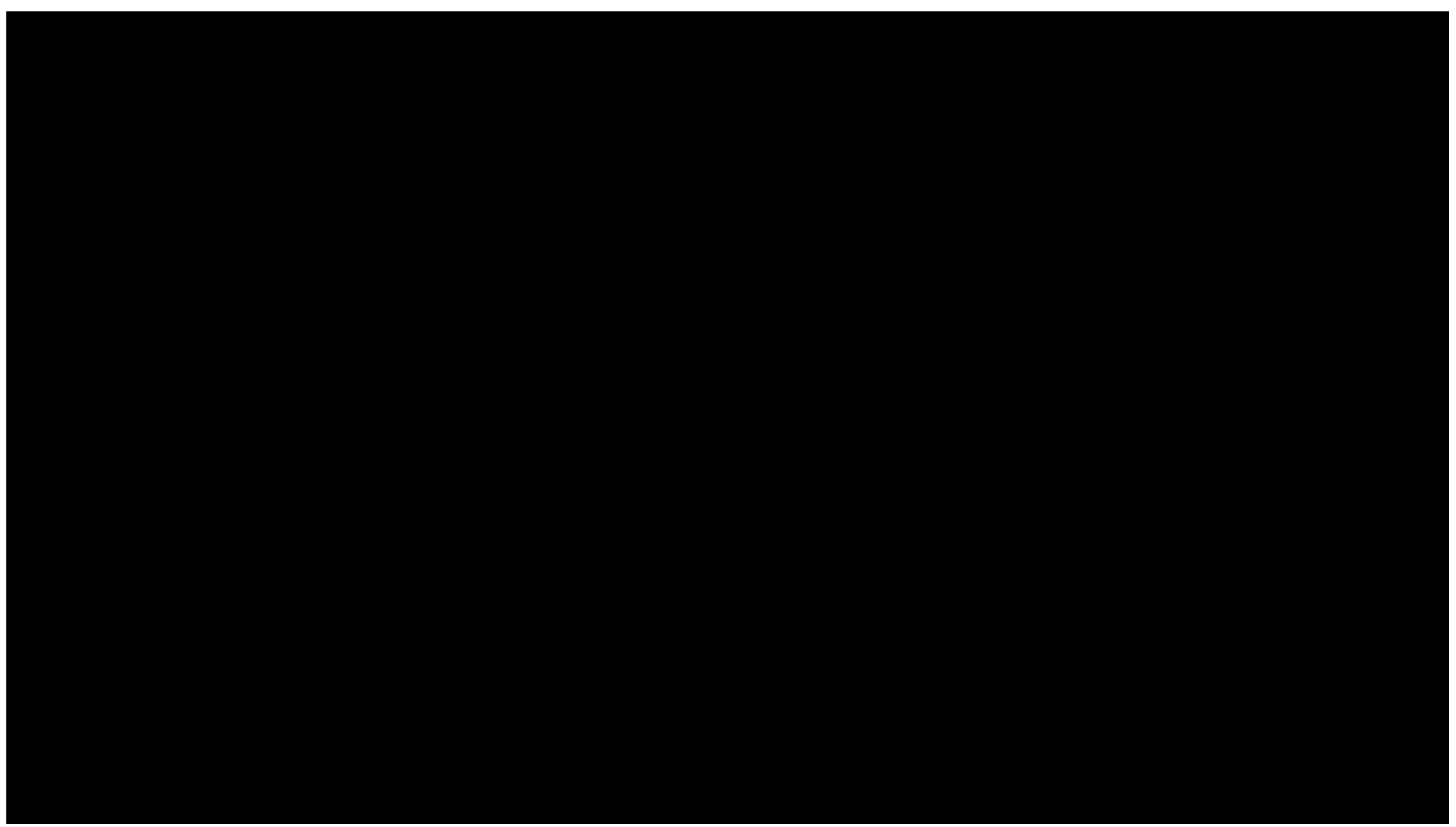




\section{SIS SLS Architecture
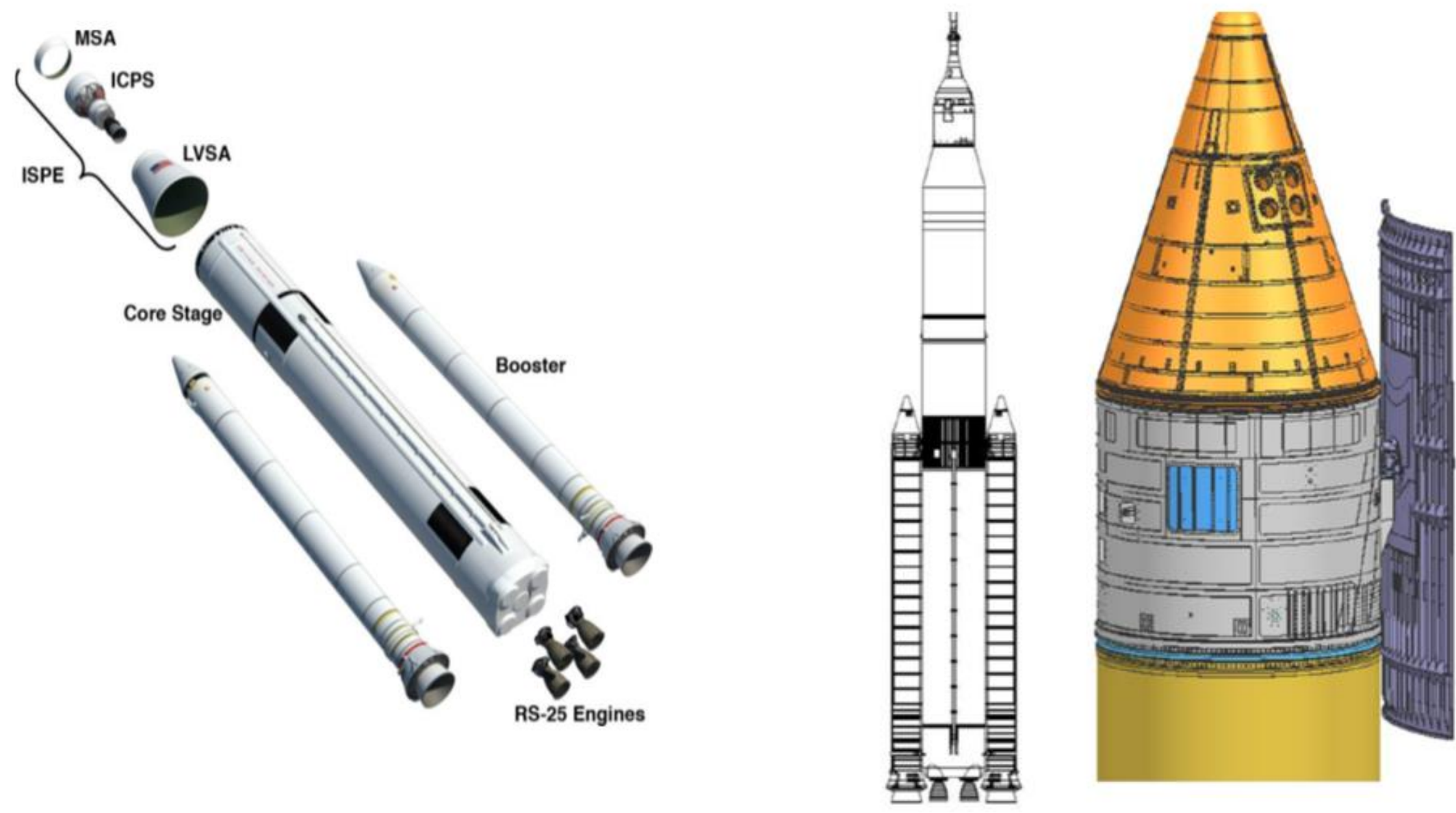


\section{Use of Heritage Hardware}

- Use of heritage hardware in new applications requires special consideration and understanding of previous lessons learned

- Lessons learned should be carefully assessed and addressed in the design, development, qualification and validation/verification for use in new applications

Lessons Learned

External, independent review teams judging the flight readiness of a vehicle should keep in mind the following key lessons gleaned from the past 20 years of space launches: 1. Propulsion systems are the primary cause of all launch failures. All propulsion test and checkout anomalies/failures demand special attention and

2. Hardware built out of normal sequence and hardware that has been reworked are major causes of failures. The processes, procedures, quality inspections, and particularly the re-test results demand special review.

3. There are no small, inconsequential changes in flight-critical components or subsystems. Systems engineering and every affected technical discipline must be involved in the assessment of all new systems and their changes. If a change is not recertified by test, the rationale must be thoroughly examined.
4. Test results that are "in-family," but near the edge of the acceptable envelope, should be thoroughly Always believe test data until they are conclusively proved wrong beyond all doubt.

5. All test anomalies/failures must be thoroughly understood and convincingly explained. All hardware that is potentially related to an unverified system anomaly/failure must be purged from the system before launch.

6. The flight environments and dynamic loads that set the qualification and acceptance test levels of each flight-critical component must be rigorously validated by a continuum of flight measurements and analyses. 


\section{Heritage Forward Skirts}

- The SRB forward skirt structural assembly is an all welded, ring stiffened monocoque cylindrical shell, primarily manufactured from 2200 series Al alloy by McDonald Douglas between 1975 and 1984

- Located between the Nose Cap and Frustum

- The skin is machined to various thicknesses around the circumference of the shell with the forward ring, thrust post fitting and attach rings machined from special forgings.

- Primary purpose is to support the core vehicle prior to launch and act as the axial thrust take out point from booster to the core vehicle during flight

- Some structural modifications for SLS but majority is same as Shuttle configuration
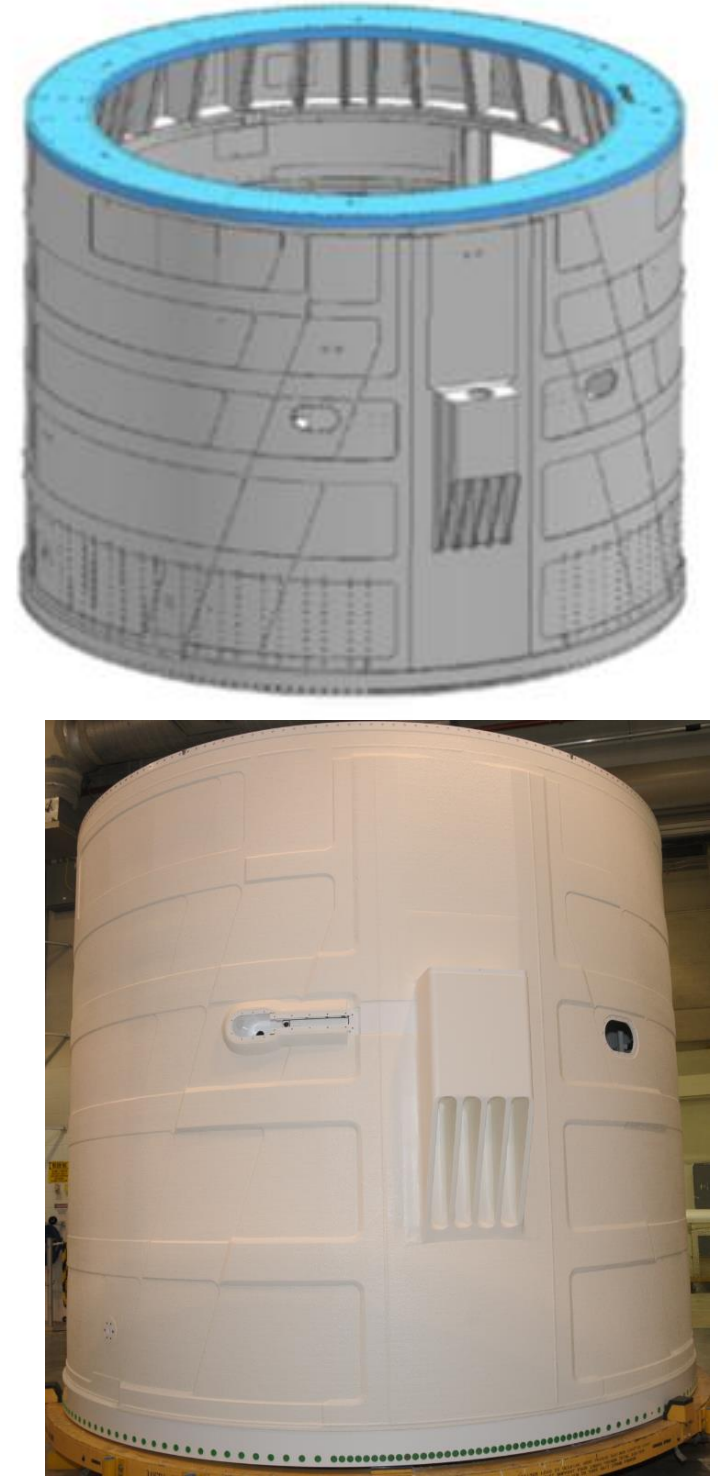


\section{Loading Condition}

- Forward Skirt Thrust Post carries axial and lateral loads at Solid Rocket Booster to Core interface

- Prelaunch: rollout, on-pad stay and core engine build up

- Ignition up to Pre-Staging, where the SRB is pyrotechnically released

- Critical load case

- $90 \%$ of thrust post ascent compression loading is due to statically determinant flight mechanics loads

- Fwd Attach Load = Booster Thrust Booster Mass * Vehicle Accel $_{x}$

- Due to the design of the interface, this axial load produces a large moment that is reacted over a relatively small fillet area that is machined into the forging

- SLS compression loads 40\% higher than Shuttle loads

- Increase in loads too high to say qualified by similarity

- Finite element models used to validate Shuttle validated via linear test results. Updated models showed highly non-linear response

- Updated Testing required

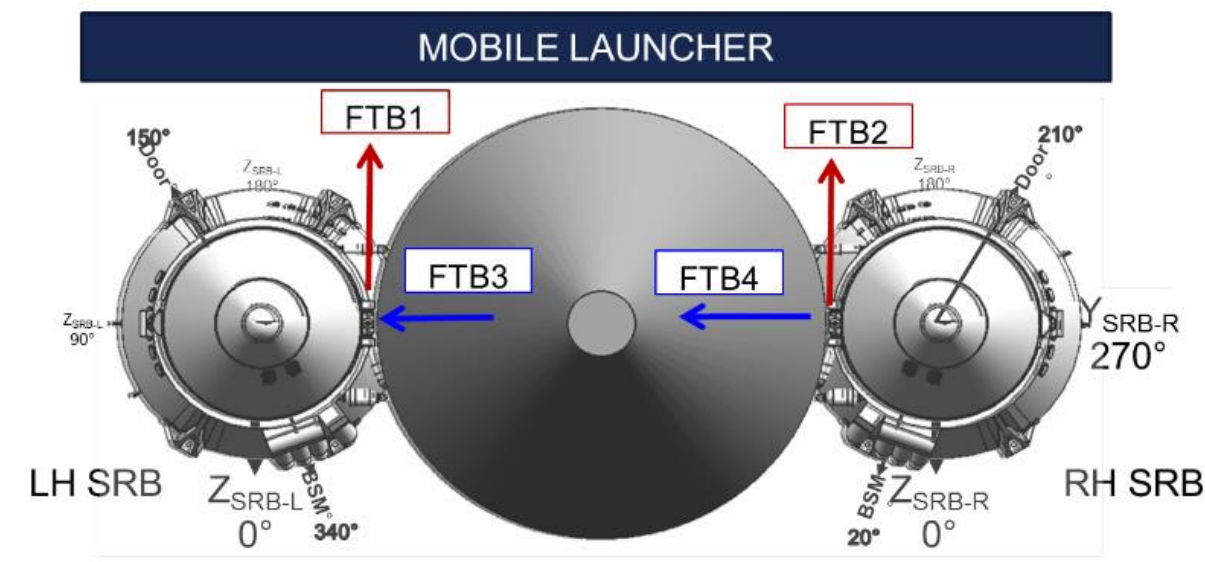

\begin{tabular}{|c|c|c|c|}
\hline Booster & Indicator & Direction & \multicolumn{1}{|c|}{ Description } \\
\hline \multirow{2}{*}{ Left } & FTB1 & Transverse & Toward the fwd skirt door is positive (+) \\
\hline & FTB3 & Radial & Radial inward is positive (+) \\
\hline & FTB5 & Axial & Compression is negative $(-)$ \\
\hline \multirow{2}{*}{ Right } & FTB2 & Transverse & Toward the fwd skirt door is positive (+) \\
\hline & FTB4 & Radial & Radial outward is positive (+) \\
\hline & FTB6 & Axial & Compression is negative $(-)$ \\
\hline
\end{tabular}

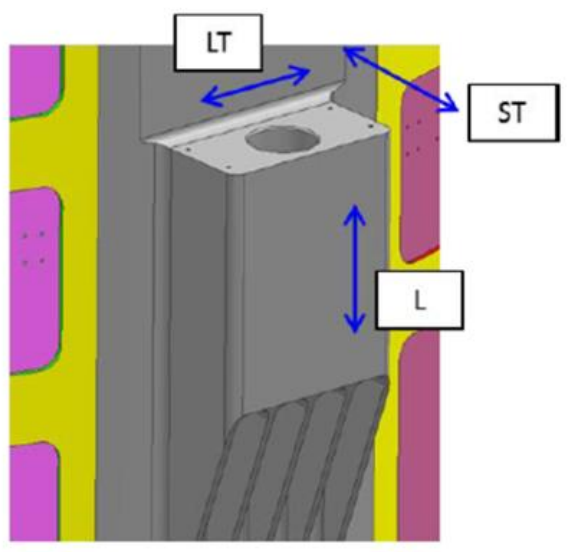




\section{SLS Testing}

- Structural testing of the heritage forward skirt was performed for the SLS program in 2014.

- Two skirts randomly selected from inventory

- Tested all critical loading conditions to $1.4 \mathrm{x}$ limit loads

- Tested both skirts to failure

- Extensive instrumentation was used to monitor the structural status of the hardware and determine failure location and time

- Strain gauges

- ARAMIS digital photogrammetry system

- String potentiometers

- Acoustic emission detectors

- Instrumented pins

- Strain gauges and ARAMIS located in region of failure

- Compared well with each other

- Used to help Finite Element Model predictions

- Both test articles failed well above the max predicted limit loads for SLS and pre-test analytical predictions

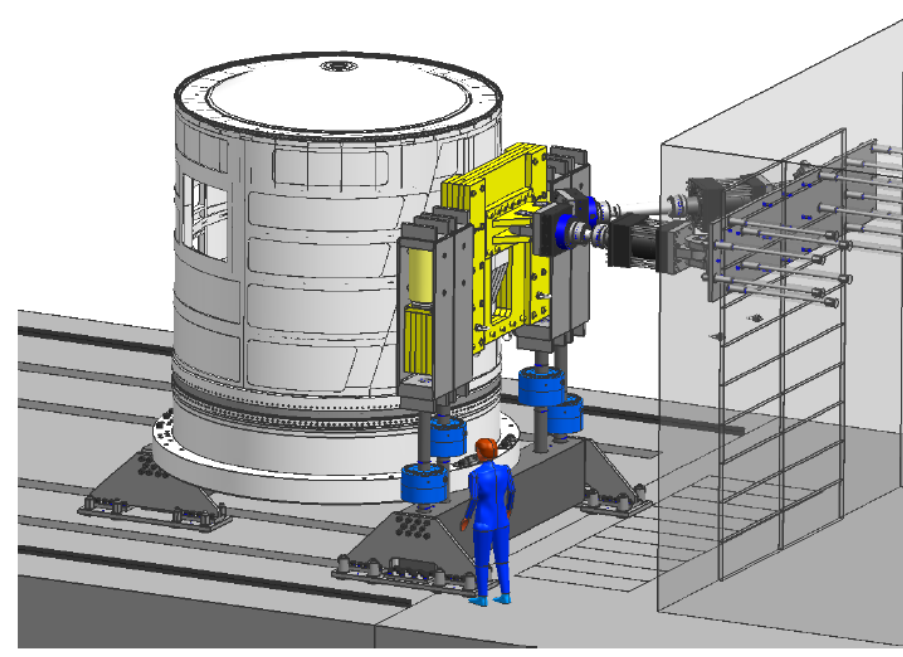
due to crack initiation and growth across the fillet radius of the fitting
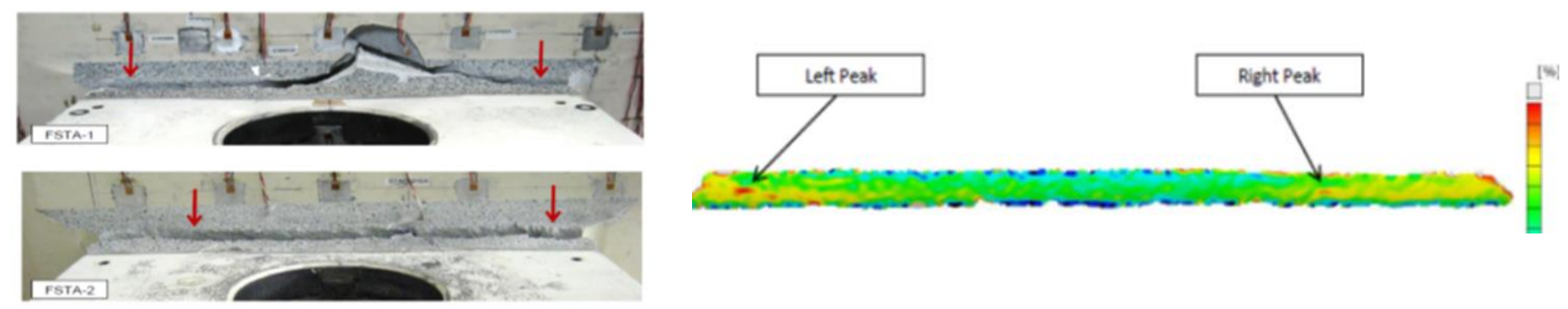


\section{Forward Skirt Failure Location}
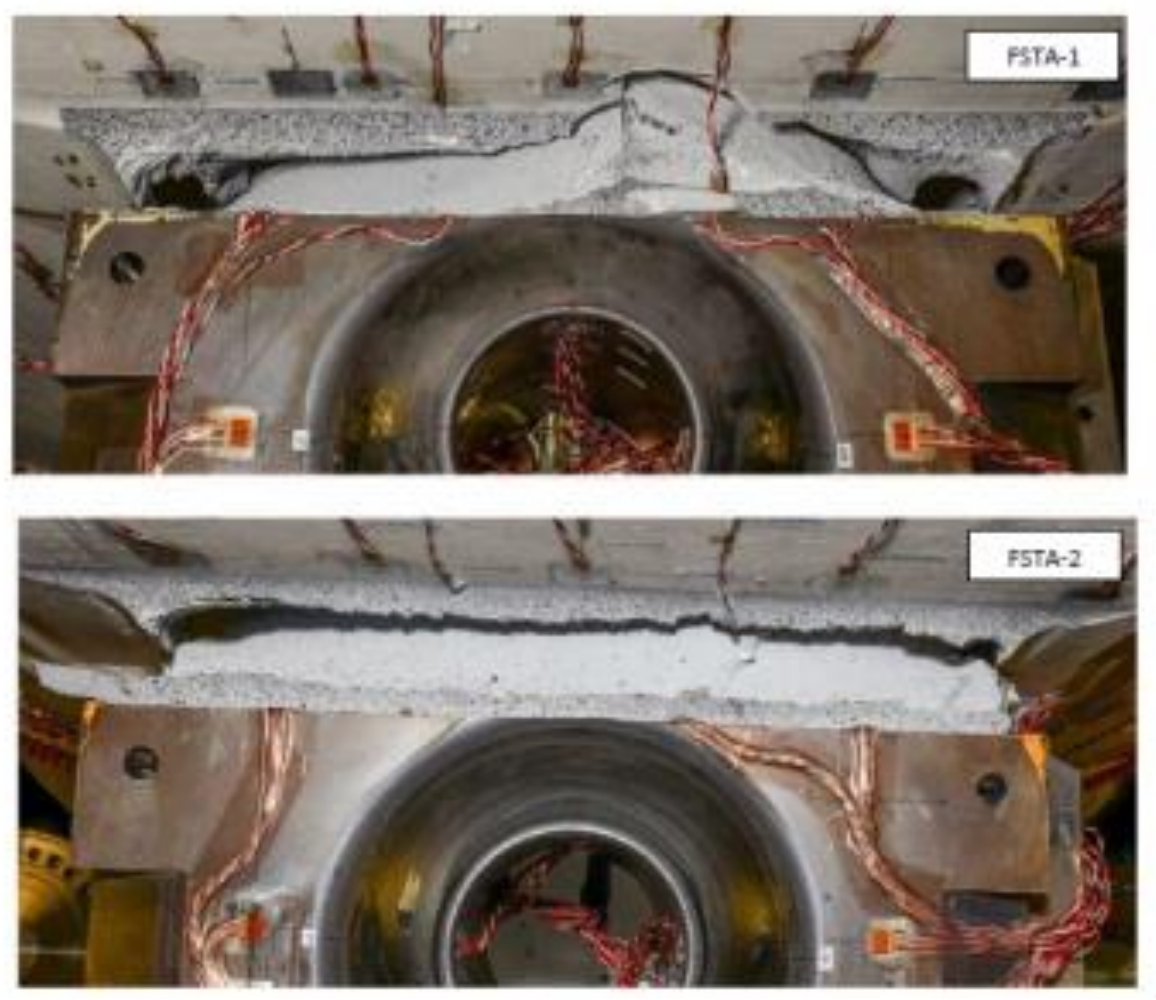

- Failure occurred in the primary load path

- Initiated in fillet region

- Thrust Post gussets subsequently buckled 


\section{Failure Criteria}

- Structural acceptability of metal structures can be determined with linear-elastic or elastic-plastic finite element analysis

- Linear-elastic analyses produce stresses that are compared to the material allowable ultimate strength

- Elastic-plastic analyses produce strains that are compared to the material allowable elongation

- Majority of heritage Shuttle hardware designed to be evaluated in linear-elastic regime

- Hardware that required elastic-plastic analysis traditionally evaluated using the Constant Critical Strain Criteria methodology, where failure occurs at the same critical strain, no matter the stress state

- Factor of Safety $=\frac{e}{E T P O}$

- e = elongation strain from material testing

- EPTO = total equivalent strain determined at $1.4 \times$ limit load from an elastic-plastic analysis with minimum required stress-strain curve

- Approaches that utilized Triaxiality Factor employed

- Triaxiality factor accounts for stress state

- Hydrostatic pressure divided by Von Mises stress

- Higher Triaxiality - lower strain to failure Lower Triaxiality - higher strain to failure

$$
T F=\frac{\sigma_{m}}{\text { Von Mises stress }}
$$




\section{Triaxiality Approach}

- Research has shown that ductile failure of metallic structures consists of three phases

- Accumulation of damage caused by plastic strain

- Initiation of fracture

- Fracture propagation resulting in failure

- Three Triaxiality based damage initiation criteria selected that had correlation with aluminum material testing

- Johnson-Cook

- Bao-Wierznicki

- Mohr-Coulomb

- References listed in paper compares the constant critical strain, Johnson-Cook and BaoWierznicki criteria for aluminum 22xx-Txxx alloy

- Failure Curves developed by plotting effective fracture strain vs Triaxiality factor 


\section{Failure Criteria}
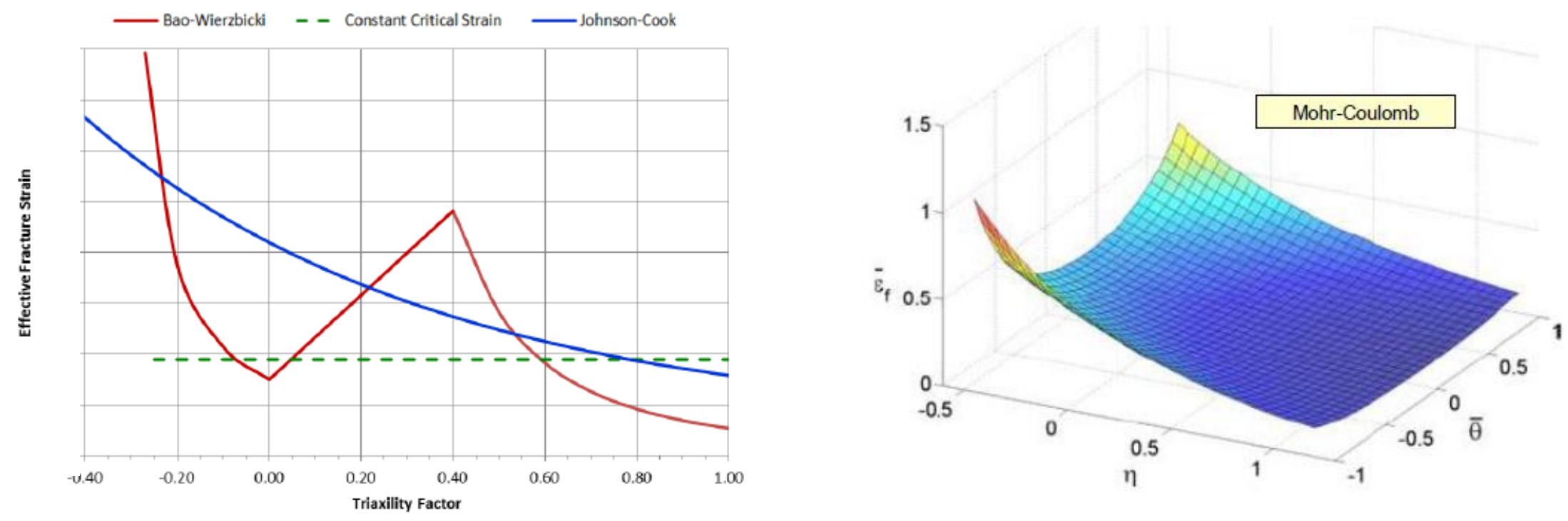

References for plots included in accompanying paper

- Bao-Wierzbicki chosen due to lack of influence of shear during thrust post failure and existence of test data with similar material 


\section{Analysis Approach}

- Two independent models were developed at MSFC

- Utilized commercial codes ANSYS and ABAQUS

- First step was to build model representing test setup

- Modeled test equipment and load sequencing

- Used material data from post-test cut samples

- Overall structure response was characterized and correlated with model

- Detailed sub-models created to characterized failure

- Develop Bao-Wierznicki failure curve for tested structures using material test data and analysis results

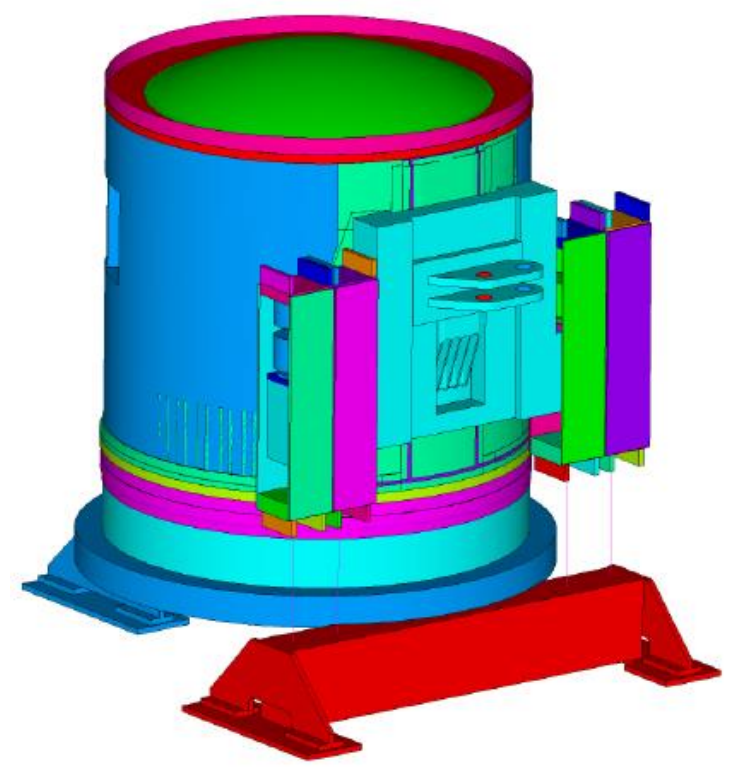

- Rerun analysis for flight conditions
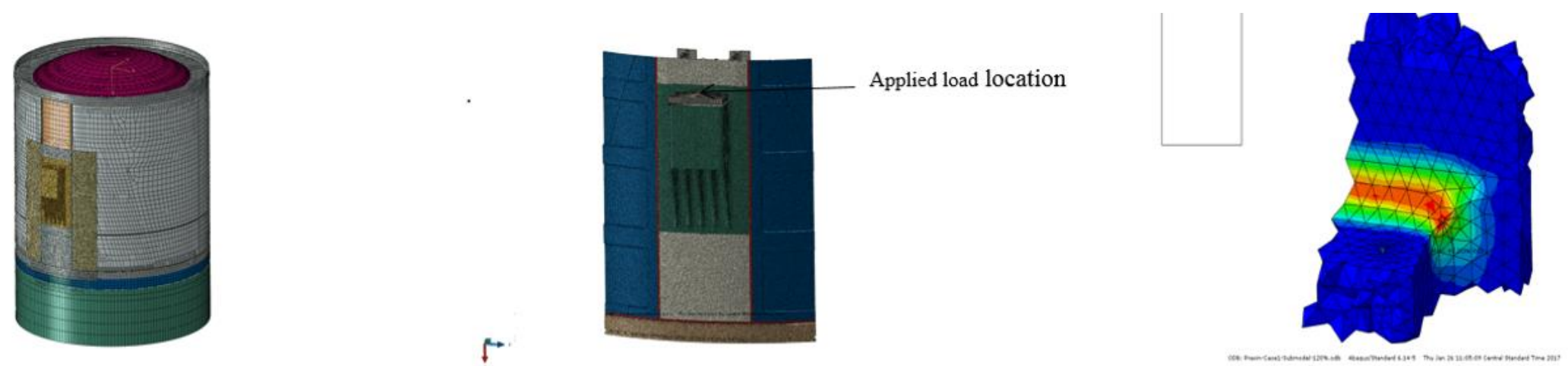

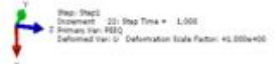




\section{Determining Factor of Safety}

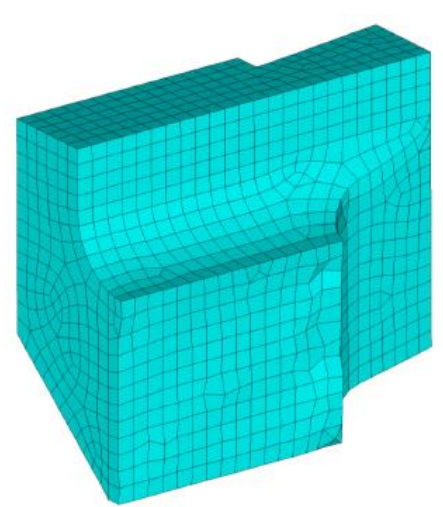

Isolate failure location

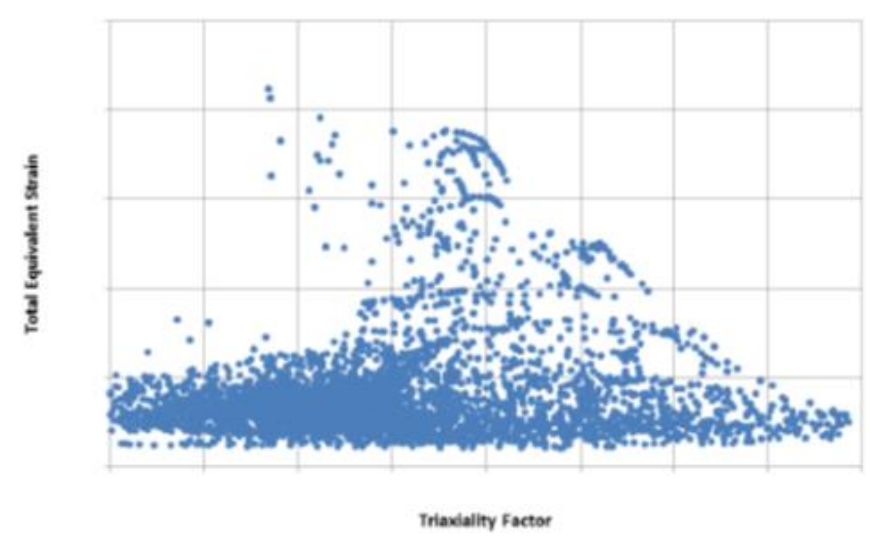

Plot Eqv. Strain vs TF at test failure load

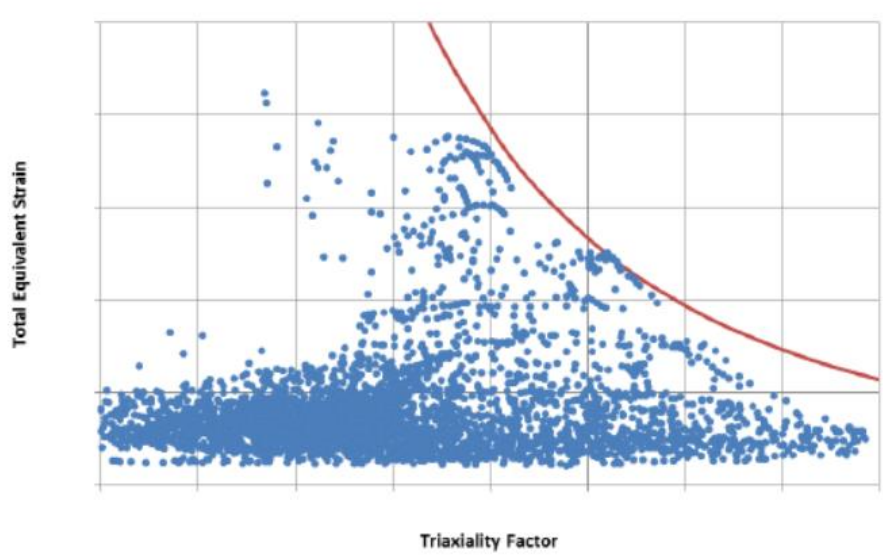

Adjust B-W curve until just touching This is failure curve

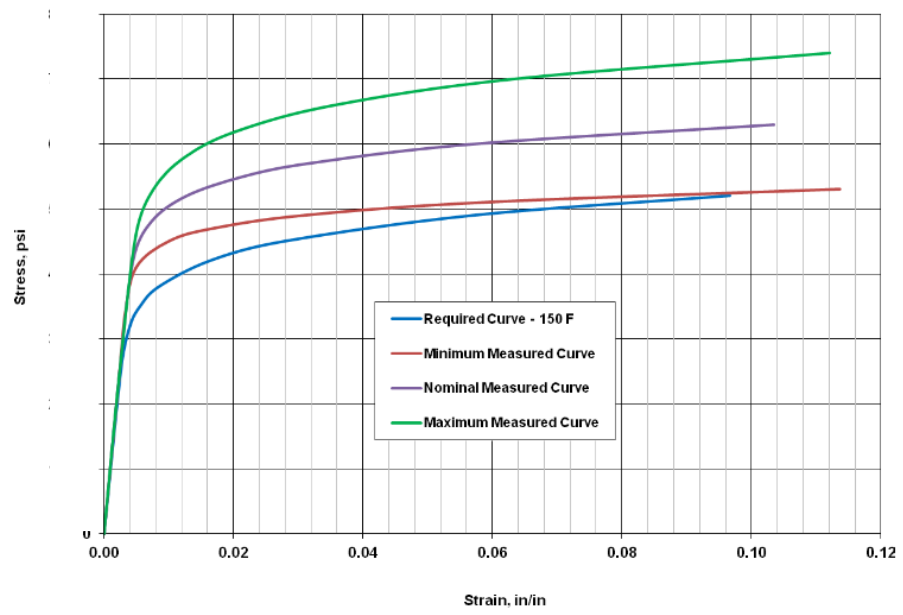

Apply flight loads, adjust model for minimum conditions and tolerances

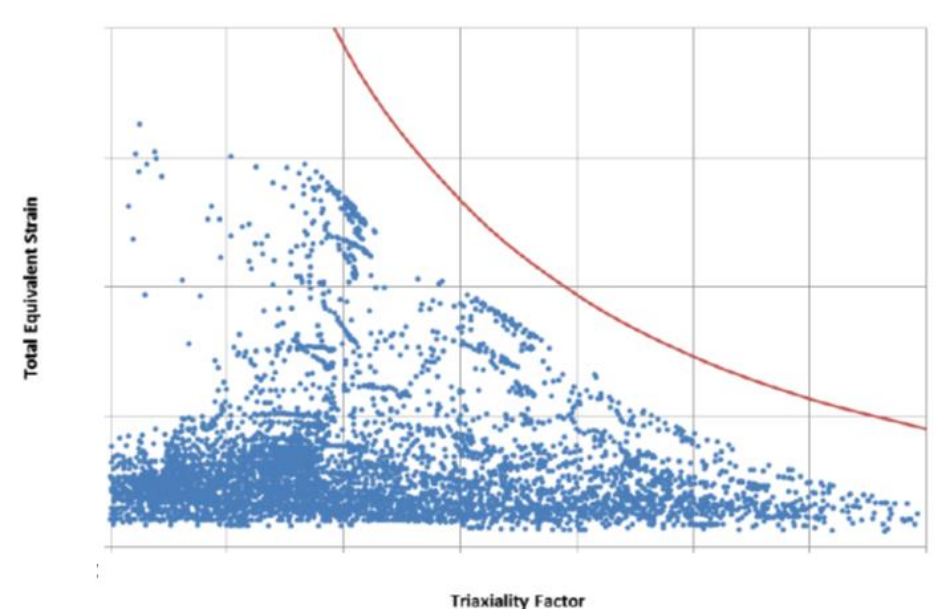

Plot Eqv. Strain vs TF at flight limit load Incrementally adjust until just touching failure curve Difference is Factor of Safety 


\section{Fracture Assessment}

- Traditional fracture assessment performed as well

- Material samples taken from thrust post radius region to develop the fracture toughness properties

- Area experiences yielding very early in load sequence

- Samples pre-strained to different values and tested to determine worst-case fracture toughness

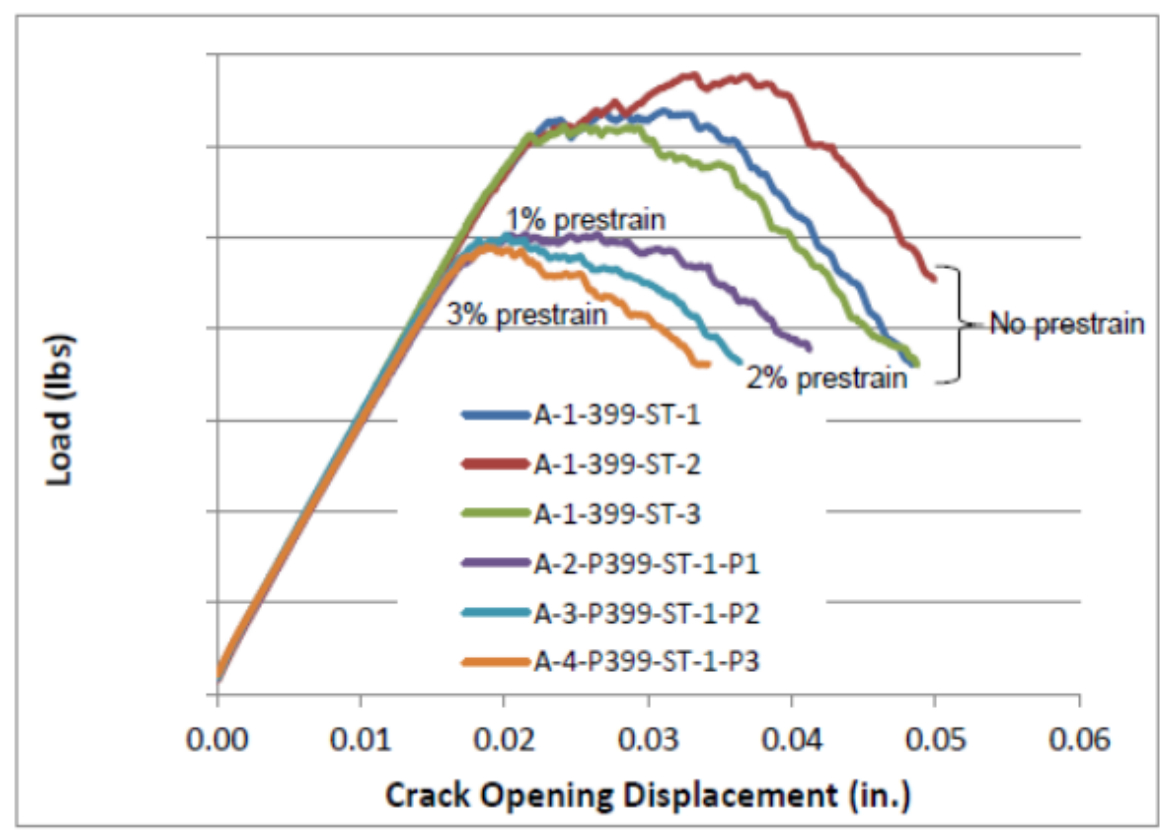




\section{Conclusions}

- A high degree of confidence in understanding loads, material properties, failure phenomena anchored with analysis and flight-like testing instrumental in requalifying the heritage Forward Skirt for the SLS program

- Well understood loads

- Majority flight mechanic statically deterministic. Key contributors understood

- Detailed Finite Element Models

- Independent Analyses

- Correlated to test

- Anchored to material test data \& minimum geometric conditions

- Failure criteria based on Triaxiality approach using test established failure criteria

- Flight factors of safety incorporate minimum material properties, minimum drawing tolerances and refurbishment considerations

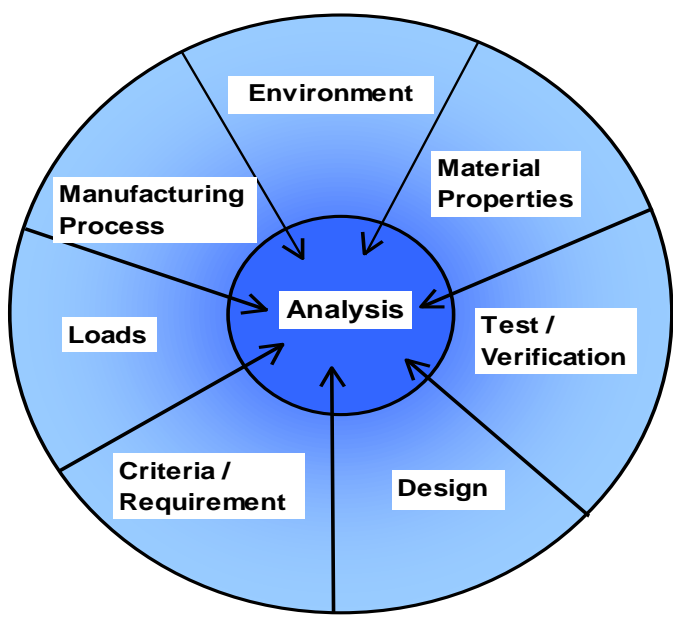

- The execution of a detailed test/qualification program and use of a more advanced analysis methodology was directly responsible for saving the Program 10's of millions of dollars that it would have cost to design, develop and qualify a new forward skirt and expediting the schedule and meets NASA's two important tenants for the SLS program: Affordability and Safety 


\section{References}

\section{- References cited in accompanying paper}

1. ESD 10001, Revision D, "Exploration Systems Development Implementation Plan" (2015)

2. ESD 10013, "Exploration Systems Development Integrated Design Definition Document" (2015)

3. NASA-STD-5001, Revision B, "Structural Design and Test Factors of Safety for Spaceflight Hardware"

4. MMPDS-04, "Metallic Materials Properties Development and Standardization (MMPDS)" (2008)

5. NASA-SP-6105, "NASA System Engineering Handbook"

6. Wierzbicki, T., "Calibration and Evaluation of Seven Fracture Models," International Journal of Material Sciences 47 (2005), pages 719-743

7. Wierzbicki, T., "On Fracture Locus in the Equivalent Strain and Stress Triaxiality Space," International Journal of Material Sciences 48 (2004), pages 81-98

8. Wierzbicki, T., "Ductile Fracture Calibration and Validation of Anisotropic Aluminum Sheets," Proceedings of the SEM Annual Conference, June 1-4, 2009

9. Teng, X., and Wierzbicki, T., "Gouging and Fracture of Engine Containment Structure Under Fragment Impact," Journal of Aerospace Engineering 21 (2008), pages 174-186

10. Brar, N. S., "Constitutive Model Constants for AL7075-T651 and AL7075-T6," American Institute of Physics 978-0-7354-07354-1006-0 (2011)

11. Brar, N. S., "Anisotropic Effects on Constitutive Model Parameters of Aluminum Alloys," American Institute of Physics 978-0-7354-1006-0 (2011)

12. Danas, K., "Influence of the Lode Parameter and the Stress Triaxiality on the Failure of Elasto-Plastic Porous Materials," International Journal of Solids and Structures 49 (2012), pages 1325-1342

13. Bai,Y., "A New Model of Metal Plasticity and Fracture with Pressure and Lode Dependence," Internal Journal of Plasticity 24 (2008), pages 1071-1096

14. Bai,Y., "Application of Extended Mohr-Coulomb Criterion to Ductile Fracture," International Journal of Fracture 161 (2010), pages 1-20

15. Wierzbicki, T., "On The Cut-off Value of Negative Triaxiality for Fracture," Engineering Fracture Mechanics 72 (2005), pages 1049-1069

16. Xue, L., "Ductile Fracture Initiation and Propagation Modeling Using Damage Plasticity Theory," Engineering Fracture Mechanics 75 (2008), pages 3276-3293

17. Xue, L., "Damage Accumulation and Fracture Initiation in Uncracked Ductile Solids Subject to Triaxial Loading," International Journal of Solids and Structures 44 (2007), pages 5163-5181

18. ABAQUS Standard Finite Element Analysis Program, Version 6.14-5

19. ANSYS APDL Finite Element Analysis Program, Version 15.0

20. ARAMIS Digital Image Correlation System 


\section{Conclusions}

- Thanks for the opportunity to be part of this special session!

Any questions? 